\title{
CrystEngComm
}

Check for updates

Cite this: CrystEngComm, 2020, 22, 3519

Received 8th March 2020,

Accepted 31st March 2020

DOI: $10.1039 / \mathrm{d} 0 \mathrm{ce} 00366 \mathrm{~b}$

rsc.li/crystengcomm

\section{High-throughput on demand access of single enantiomers by a continuous flow crystallization process $\uparrow$}

\author{
Fabio Cameli, ${ }^{a}$ Christos Xiouras (D) ${ }^{* b}$ and Georgios D. Stefanidis (D)*ac
}

\begin{abstract}
A novel continuous flow reactive crystallization process for the in situ on-demand access of single enantiomer crystals is reported and exemplified for a chiral pharmaceutical intermediate that crystallizes as a racemic conglomerate. During this process, a nearly racemic feed suspension with a racemization catalyst is circulated through a tubular coiled milli-reactor immersed in two thermostatic baths set at different temperatures. This flow configuration enables rapid heat transfer, which in turn results in successive spatial cycles of dissolution and re-crystallization carried out at extremely short residence times, unattainable in batchwise operations. By tuning the number of cycles, residence time per cycle and feed suspension density we show that unprecedented productivities $\left(>20 \mathrm{~g} \mathrm{~L}^{-1} \mathrm{~h}^{-1}\right)$ of the preferred enantiomer at purities $>98 \%$ can be attained that could easily suit industrial demand in a directly scalable process.
\end{abstract}

\section{Introduction}

Amongst the plethora of methods for chiral separation, crystallization-enhanced deracemization processes have attracted much interest in the pharmaceutical industry due to complete enantiopurity and maximum theoretical solid recovery achievable. ${ }^{1}$ Such deracemization processes rely on partial dissolution and re-crystallization of a nearly racemic suspension of chiral conglomerate crystals via either mechanical forces ${ }^{2}$ or thermal oscillations ${ }^{3}$ in the presence of a racemization reaction. While the mechanisms leading to deracemization in those processes have been thoroughly investigated, ${ }^{4}$ all deracemization process schemes developed so far operate in batch mode, while direct scale-up of these configurations as such has been both limited and unsuccessful. ${ }^{3 g}$

Continuous manufacturing has been adopted by the pharmaceutical industry as the way forward, ${ }^{5}$ exhibiting unique benefits such as the accessibility to extreme reaction conditions and hazard control, ${ }^{5 a, b}$ lower plant footprint and waste production, ${ }^{5 c, d}$ improved supply chain, flexibility of production $^{5 d}$ and a high level of control within a quality-by-

\footnotetext{
${ }^{a}$ Process Engineering for Sustainable Systems (ProcESS), Department of Chemical Engineering, KU Leuven, Celestijnenlaan 200F, 3001 Leuven, Belgium.

E-mail: georgios.stefanidis@kuleuven.be

${ }^{b}$ Crystallization Technology Unit (CTU), Janssen Research \& Development, Janssen Pharmaceutical Companies of Johnson \& Johnson, Tournhoutseweg 30, 2340, Beerse, Belgium.E-mail: CXiouras@its.jnj.com

${ }^{c}$ School of Chemical Engineering, National Technical University of Athens, 9, Heroon Polytechniou Str., Zografos, Athens, Gr-15780, Greece

$\dagger$ Electronic supplementary information (ESI) available. See DOI:10.1039/ d0ce00366b
}

design (QbD) framework. ${ }^{5 c}$ In particular to crystallization processes, such benefits have been demonstrated in continuous antisolvent crystallizations, ${ }^{6}$ oscillatory baffled flow crystallizers ${ }^{7}$ as well as in integrated reaction, crystallization and formulation schemes for the end-to-end manufacture of pharmaceuticals. ${ }^{8}$

While a few modelling studies have demonstrated the feasibility of extending continuous crystallization processes to the deracemization of chiral compounds, ${ }^{9}$ also in combination with racemization reactions, ${ }^{9 a}$ an experimental proof-of-principle for such a process remains unreported. In this context, small diameter $(\mu \mathrm{m}-\mathrm{mm})$ flow reactor technology is expected to offer unique advantages for deracemization processes via e.g. temperature cycles, as heat can be added and removed efficiently owing to the high surface-to-volume ratio and small volumes involved in such configurations. $^{5 e}$ Additionally, such technology is considerably easier to scale up compared to batch processing by e.g. "smart dimensioning" or numbering up. ${ }^{5 a}$ To our knowledge, no deracemization or any other chiral crystallization process for that matter has been reported in such flow-through (milli-)reactor configuration.

Herein, we show for the first time that fully continuous and automated deracemization is possible for an important chiral pharmaceutical intermediate by employing spatial thermal oscillations in a tubular flow milli-reactor. Without extensive optimization, we show that such continuous operation delivered approximately an order of magnitude higher productivities compared to similar batch processes offering tremendous possibilities for intensifying and scaling up this deracemization process. 


\section{Experimental section}

\section{Model compound}

Compound 1, (2-isopropyl-3-hydroxy-3-phenylisoindolin-1-one) belongs to the class of isoindolin-1-ones, which are important building blocks for several natural products and pharmaceuticals. $^{10 a}$ While various synthetic routes for producing chiral isoindolin-1-ones exist, only few asymmetric syntheses of such molecules are known in the literature. ${ }^{10 b}$ Previous studies have shown that $\mathbf{1}$ fulfils the necessary prerequisites for deracemization, i.e. a) conglomerate crystallization and b) facile racemization in the liquid phase (Scheme 1). ${ }^{11}$ In our previous work, ${ }^{3 h}$ we studied extensively the deracemization behaviour of $\mathbf{1}$ in batch temperature cycling experiments carried out in a microwave reactor and underscored the key role of stereoselective secondary nucleation in the deracemization process. For this reason, we selected $\mathbf{1}$ as a model compound to perform the continuous deracemization experiments reported here, due to our experience with the compound and the availability of previous batch deracemization data that can be directly compared with the continuous deracemization experiments. To this end, rac-1 was synthesized in our lab using the same procedure as in our previous work, ${ }^{3 h}$ also reported in the ESI. $\dagger$

\section{Set-up}

In order to investigate the feasibility of continuous deracemization of $\mathbf{1}$ via spatial thermal oscillations, we designed a flow milli-reactor that employed a helically coiled tube (PFA, inner $\varnothing 1.59 \mathrm{~mm}$ ), in which two water baths were utilized to provide constant temperature in the different zones of dissolution and crystallization as shown in Fig. 1. In all experiments, the temperatures of the cold and hot baths were kept at $25{ }^{\circ} \mathrm{C}$ and $70{ }^{\circ} \mathrm{C}$, respectively. Different configurations were tested, in which the total length of the tube $(L)$ varied in order to adjust the cycle residence time in the dissolution $\left(\tau_{\mathrm{c}, 1}\right)$ and crystallization zones $\left(\tau_{\mathrm{c}, 2}\right)$ at a constant suspension flow rate of 3-6 $\mathrm{mL} \mathrm{min}^{-1}$.

Hence, the tube length in each dissolution passage varied from $0.25 \mathrm{~m}$ to $2 \mathrm{~m}$ resulting in $\tau_{\mathrm{c}, 1}$ between $5 \mathrm{~s}$ and $80 \mathrm{~s}$ while the length in the low temperature zone varied between $0.5 \mathrm{~m}$ and $4 \mathrm{~m}$, corresponding to $\tau_{\mathrm{c}, 2}$ between $10 \mathrm{~s}$ and $160 \mathrm{~s}$.

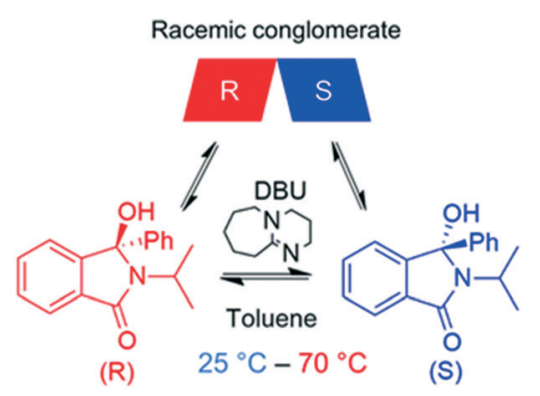

Scheme 1 Racemization reaction of 1 in toluene using catalytic DBU. 1 crystallizes as a racemic conglomerate, i.e. $R$ and $S$ enantiomers discriminate in the solid state.

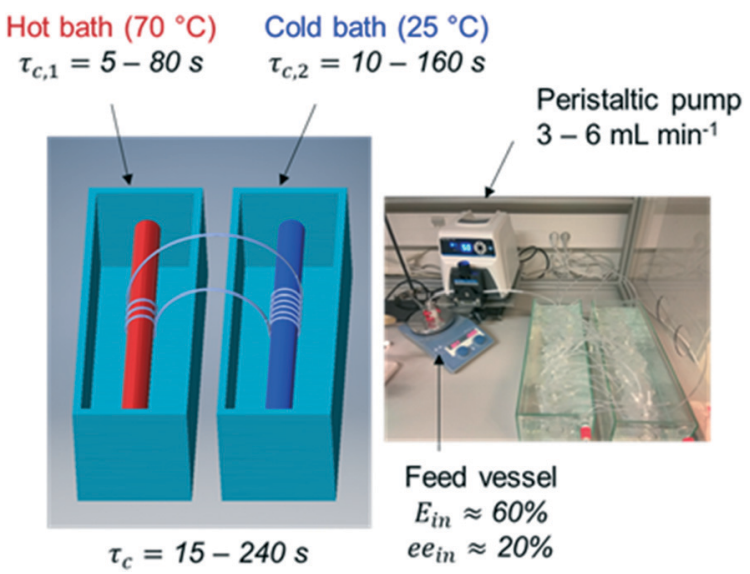

Fig. 1 Tubular flow reactor employed for the deracemization of 1 via spatial cycles of dissolution and re-crystallization.

Since crystallization is typically slower than dissolution, $\tau_{\mathrm{c}, 2}$ was kept two times higher than $\tau_{\mathrm{c}, 1}$ in all configurations. Hence, the cycle residence time: $\tau_{\mathrm{c}}=\tau_{\mathrm{c}, 1}+\tau_{\mathrm{c}, 2}$ varied between $15 \mathrm{~s}$ and $240 \mathrm{~s}$ in the different experiments.

In order to run each configuration for various number of cycles $(N)$, each set-up employed only one thermal cycle (i.e. one dissolution and crystallization passage respectively) working in a loop. To enable such operation, the nearly racemic feed suspension (ee $\approx 20 \%$, thus $E_{\text {in }} \approx 60 \%$ in favour of the $S$ enantiomer) was initially fed through the tubular reactor, and subsequently the two ends of the tube were tied together with a connecting fitting. Thereafter, the reactor worked without interruptions for a given set of $N$ cycles, resembling a fully continuous tubular reactor with a total length of $N \cdot L$. At the end of each run, the connecting fitting was uncoupled, and the entire suspension was filtered on a glass filter to determine yield, productivity and enantiomeric purity for each run.

\section{Measurement of enantiomeric purity}

The final enantiomeric purity of the dried product crystals $\left(E_{\mathrm{f}}\right)$ was determined by chiral HPLC in a Lux Amylose-1

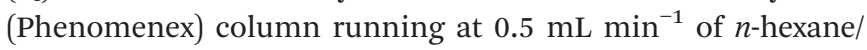
ethanol $95 / 5(\mathrm{v} / \mathrm{v} \%)$. The enantiomers were detected by a diode array detector (DAD) at a wavelength of $254 \mathrm{~nm}$ and the enantiomeric purity of the preferred ( $S$ in this case) enantiomer was calculated as:

$$
E=\frac{A_{S}}{A_{R}+A_{S}}
$$

where $A_{R}$ and $A_{S}$ represent the peak areas for the $R$ and $S$ enantiomers in the chromatograms, respectively.

\section{Solid yield and process productivity}

The final overall solid yield $(Y)$ was calculated based on the outlet solute concentration of 1 recovered from the process and the solubility at $25^{\circ} \mathrm{C}$ : 


$$
Y=1-\frac{\left(C_{\mathrm{out}}-C_{25}^{*}\right)}{\rho_{\mathrm{s}, \mathrm{f}}}
$$

where $C_{\text {out }}$ is the solute concentration of $\mathbf{1}$ measured in the outlet stream ( $\mathrm{g} \mathrm{L}_{\text {solvent }}{ }^{-1}$ ), $C_{25}^{*}$ is the solubility of rac-1 at 25 ${ }^{\circ} \mathrm{C}\left(20.7 \mathrm{~g} \mathrm{~L}_{\text {solvent }}{ }^{-1}\right)$ and $\rho_{\mathrm{s}, \mathrm{f}}$ is the feed suspension density at $25{ }^{\circ} \mathrm{C}$ (constant at $45.4 \mathrm{~g} \mathrm{~L}_{\text {solvent }}{ }^{-1}$ unless stated otherwise). Both solute concentration of the outlet and the solubility concentration were measured via UV spectroscopy in a UV/ VIS Lambda 365, Perkin Elmer spectrophotometer.

The productivity of the desired enantiomer $\left(P ; \mathrm{g} \mathrm{L}_{\text {solvent }}{ }^{-1}\right.$ $\mathrm{h}^{-1}$ ) was calculated according to: ${ }^{3 f}$

$$
P=\frac{\rho_{\mathrm{s}, \mathrm{f}} \cdot Y}{N \cdot \tau_{\mathrm{c}}}\left(E_{\mathrm{f}}-E_{\text {in }}\right)
$$

where $Y$ is the overall solid yield (eqn (2)), $E_{\mathrm{F}}$ is the final enantiomeric purity measured by chiral HPLC (eqn (1)) and $E_{\text {in }} \approx 60 \%$ is the known initial enantiomeric purity. $N$ and $\tau_{\text {c }}$ are the number of cycles and residence time per cycle $(h)$, respectively, for the various reactor configurations.

\section{Results and discussion}

\section{Thermal analysis of the flow reactor}

Initial characterization of the flow reactor involved the determination of the thermal profiles along the length of the tube, as well as characterization of the dissolution and crystallization kinetics for the various cycle residence times $\left(\tau_{\mathrm{c}}\right)$ examined. In Fig. 2 the temperature profiles attained in the reactor are reported as a function of tube length, measured by an infrared camera, where zero length corresponds to the point immediately after exiting the hot bath. Fig. 2 shows that the temperature of the tube leaving the hot bath is comparable among the different experiments although inferior to the bath temperature of $70^{\circ} \mathrm{C}$, likely due to fast cooling by natural convection when the tube meets ambient air at room temperature. Subsequently, along the length of the reactor, the solution is cooled and temperatures

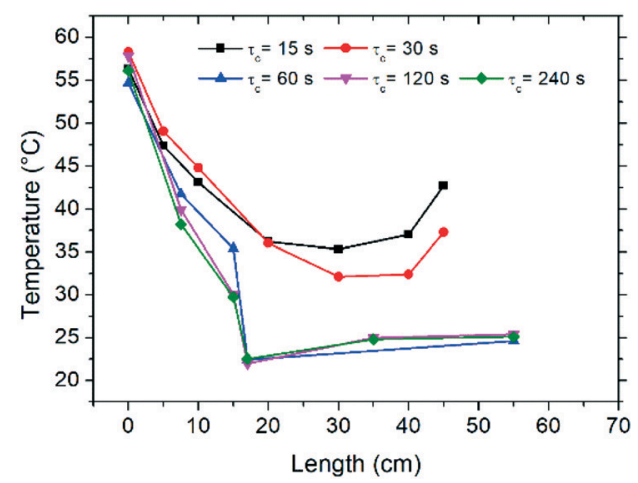

Fig. 2 Temperature profiles along the reactor length in the cooling section of the reactor (after exiting the hot bath) with varying cycle residence times $\left(\tau_{\mathrm{c}}\right)$. Due to practical limitations, experiments at $\tau_{\mathrm{c}}=15$ $\mathrm{s}$ and $\tau_{\mathrm{c}}=30 \mathrm{~s}$ were only cooled by natural convection in contact with air at room temperature. close to $25{ }^{\circ} \mathrm{C}$ are achieved for most experiments. Due to practical considerations, experiments with $\tau_{\mathrm{c}}=15-30 \mathrm{~s}$ could not be cooled in the bath and were only air-cooled by natural convection, which as shown in Fig. 2 provokes dampened thermal sweeps with minimum temperature values of about $35{ }^{\circ} \mathrm{C}$. Nonetheless, the temperature profiles reported in Fig. 2 clearly show that the flow configuration employed here enables excellent heat transfer, which is very difficult to attain in typical batchwise operations. This in turn permits cycles of dissolution and crystallization at unprecedented short times.

\section{Dissolution and crystallization rates}

The kinetics of dissolution and re-crystallization, which in turn determine the mass involved in the deracemization process, were evaluated by carrying out measurements of solute concentration at the end of the dissolution and crystallization segments as a function of residence time. The results are reported in Fig. 3 in which one can notice that both dissolution and crystallization do not reach full equilibrium. As expected, the longer the residence time in both hot and cold parts the closer to solubility limits the system operates. In particular, for the dissolution stage, up to
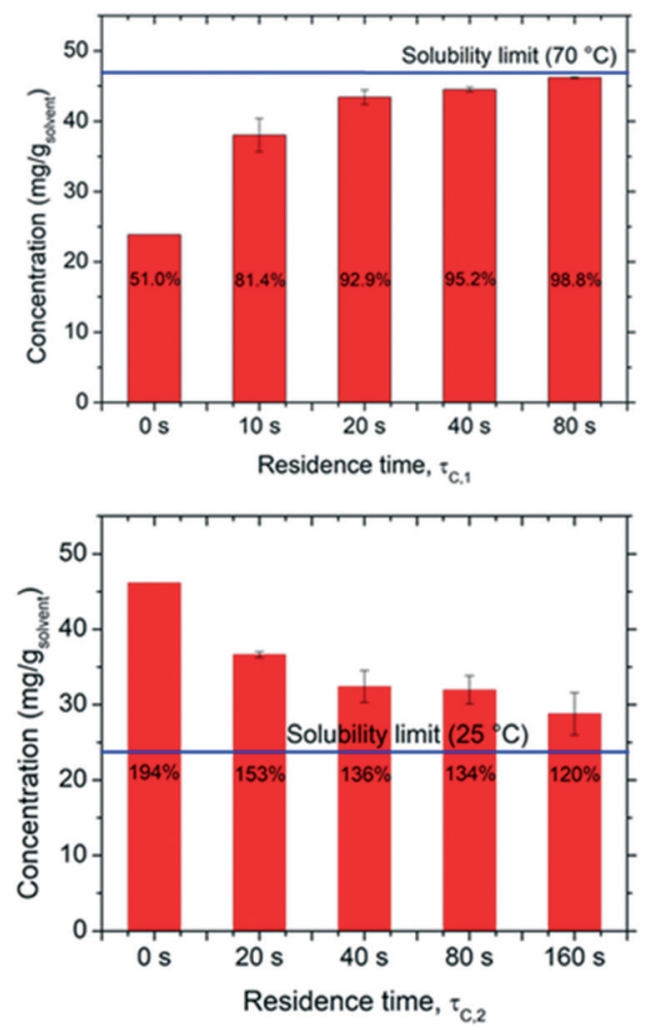

Fig. 3 Outlet solute concentration at different residence times in the hot $\left(\tau_{c, 1}\right.$, top) and cold $\left(\tau_{c, 2}\right.$, bottom) zones indicating the degree of dissolution and crystallization with respect to the solubility limits (blue lines). Bars at $0 \mathrm{~s}$ residence times are the theoretical equilibrium concentrations at $25{ }^{\circ} \mathrm{C}$ (beginning of dissolution) and $70{ }^{\circ} \mathrm{C}$ (beginning of crystallization). For the crystallization experiments (bottom), the residence time in the dissolution stage preceding the crystallization stage was constant at $80 \mathrm{~s}$. 
$98.8 \%$ of the solubility at $70{ }^{\circ} \mathrm{C}$ is achieved with $\tau_{\mathrm{c}, 1}=80 \mathrm{~s}$, while a $\tau_{\mathrm{c}, 1}=20 \mathrm{~s}$ is already sufficient to reach more than $90 \%$ of the solubility. Likewise, the rate of solution desupersaturation due to crystallization is influenced by the residence time, with longer residence times leading to solution concentrations closer to the solubility at $25{ }^{\circ} \mathrm{C}$. However, it is evident that most dissolution and crystallization already occur at short residence times (up to $\tau_{\mathrm{c}, 1}=20 \mathrm{~s}$ and $\tau_{\mathrm{c}, 2}=40 \mathrm{~s}$ ), with negligible mass dissolving/ crystallizing after those times. This pertains to the fact that dissolution and crystallization kinetics are initially much faster due to the high initial super(under)saturations attained. Thus, short cycle residence times are advantageous, as they avoid operating at low driving forces where dissolution/ crystallization kinetics are slow. For example, in a period of $240 \mathrm{~s}$, one can perform a single cycle featuring $\tau_{\mathrm{c}, 1}=80 \mathrm{~s}$ and $\tau_{\mathrm{c}, 2}=160 \mathrm{~s}$ which would involve $\sim 17.4 \mathrm{mg} \mathrm{g}_{\text {solvent }}{ }^{-1}$ in the dissolution/recrystallization process. Alternatively, in the same time period of $240 \mathrm{~s}, 4$ cycles featuring $\tau_{\mathrm{c}, 1}=20 \mathrm{~s}$ and $\tau_{\mathrm{c}, 2}=40 \mathrm{~s}$ can be performed, each of which would involve 11 $\mathrm{mg} \mathrm{g}_{\text {solvent }}{ }^{-1}$, giving a total of $44 \mathrm{mg} \mathrm{g}_{\text {solvent }}{ }^{-1}$ involved in the dissolution/recrystallization process.

\section{Effect of residence time on deracemization}

In order to determine whether enantiomeric enrichment occurs in these configurations as well as the minimum number of cycles required to do so, we conducted series of continuous deracemization experiments at 20, 50 and 100 cycles for the various cycle residence times, $\tau_{\mathrm{c}}$ values of 30,60 , 120 , and $240 \mathrm{~s}$, corresponding to the $\tau_{\mathrm{c}, 1}$ and $\tau_{\mathrm{c}, 2}$ values reported in Fig. 3. All experiments were started from an initial enantiomeric excess of $20 \%$. It is also noted, that in all experiments, the initial enantiomeric imbalance was created by mixing small enantiopure crystals of $\mathbf{1}$ (obtained in a previous deracemization run) with larger rac-1 crystals (synthesized according to the procedure reported in the ESI $\dagger$ ). Thus, besides the enantiomeric mass imbalance, there is also a small size imbalance between the enantiomers, that could adversely affect deracemization, since the smaller enantiopure crystals can kinetically dissolve and convert to the counter enantiomer during the heating phase. While this effect may well play a role in the observed deracemization kinetics, its magnitude is expected to be similar among the different experiments since the same enantiomeric imbalance was used. Thus, a relative comparison of the deracemization rates among the reported experiments is still possible.

Fig. 4 shows that continuous deracemization is well feasible, as every configuration led to substantial increase in the enantiomeric purity from $60 \%$ up to values $>96 \%$. Starting from an even lower initial enantiomeric imbalance is expected to also lead to complete deracemization, as shown previously in batch experiments, ${ }^{3}$ but it is undesirable due to the slow deracemization rates attained that could lead to low productivity. ${ }^{3 f}$ In order to prove that deracemization is due to temperature cycles, a continuous experiment (ESI $\dagger$ ) at a
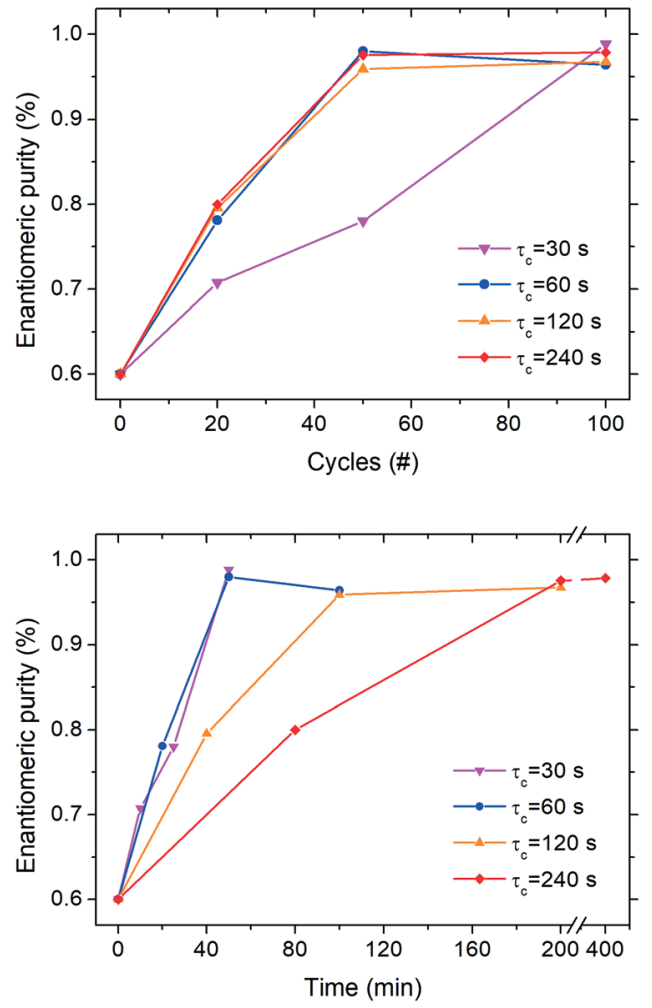

Fig. 4 Evolution of solid-state enantiomeric purity (in the $S$ enantiomer) during continuous deracemization experiments per cycle (top) and time-based (bottom) at different cycle residence times (30, 60,120 and $240 \mathrm{~s}$ ). In all experiments, feed suspension density was $45.4 \mathrm{~g} \mathrm{~L}_{\text {solvent }}{ }^{-1}$.

constant temperature $\left(25^{\circ} \mathrm{C}\right)$ was also run using only the cold bath $\left(\tau_{\mathrm{c}}=60 \mathrm{~s}\right)$ with a suspension featuring $20 \%$ enantiomeric excess. During that experiment, no substantial enantiomeric enrichment was observed for more than 100 cycles indicating that the reason for the enantiomeric enrichment in the continuous experiments is indeed the successive cycles of dissolution and re-crystallization induced by spatial thermal oscillations.

It is also noticeable (Fig. 4, top) how little difference in the deracemization rate per cycle is attained at different residence times presumably due to the similar dissolution/crystallization rates achieved for $\tau_{\mathrm{c}}>60 \mathrm{~s}$ (Fig. 3). Nevertheless, the experiment with $\tau_{\mathrm{c}}=30 \mathrm{~s}$ clearly features a lower deracemization rate per cycle, possibly due to the lower mass involved per cycle. While most experiments reach maximum purity already at 50 cycles, the aforementioned configuration requires 100 cycles to achieve similar purity. However, Fig. 4 (bottom) shows that shorter residence times lead to an overall shorter time to reach enantiomeric purity, as the lower deracemization capacity per cycle is overcompensated by the fact that many more cycles are possible during the same time period, in accordance to our previous observations in batch deracemization via temperature cycles. ${ }^{3 c}$

In order to show that the loop reactor configuration employed here for convenience is equivalent to a fully continuous tubular reactor that can be used in industry, we 


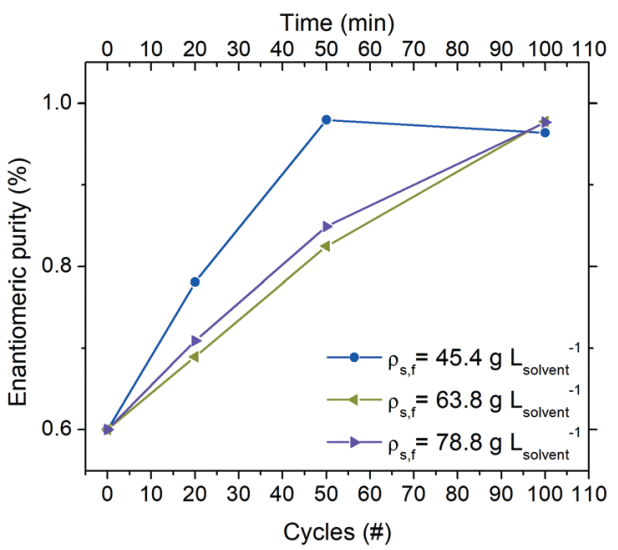

Fig. 5 Evolution of solid-sate enantiomeric purity (in the $S$ enantiomer) during continuous deracemization experiments at different feed suspension densities. In all experiments, cycle residence time was: $\tau_{\mathrm{c}}=60 \mathrm{~s}$.

repeated the experiment at $\tau_{\mathrm{c}}=120 \mathrm{~s}$ in a fully continuous manner by employing a $60 \mathrm{~m}$ long tube (seen in Fig. 1, right) featuring 20 successive cycles of heating and cooling without recirculation of the suspension (single passage). The initially scalemic suspension $\left(E_{\text {in }}=85 \%\right)$ used in that experiment reached a final enantiomeric purity of $96 \%$ at the outlet of the reactor. Since a similar enantiomeric purity increase was obtained in the loop experiment with $\tau_{\mathrm{c}}=120 \mathrm{~s}$ after 20 cycles (Fig. 4, top), we became convinced that the loop systems used for the analysis of the residence time can be considered as reliable reproductions of fully continuous configurations applicable at industrial scale.

\section{Effect of feed suspension density on deracemization}

Operating the continuous reactor at a higher suspension density is expected to directly influence productivity (eqn (3)). To this end, three experiments at the same residence time $\left(\tau_{\mathrm{c}}\right.$ $=60 \mathrm{~s}$ ) were conducted in order to investigate the behaviour of the system when a higher amount of crystals is employed for deracemization.

As the thermal profile was identical in all conditions, a lower percentage of crystal mass is involved in the dissolution/crystallization stages when the process is run with higher suspension densities. Therefore, from Fig. 5 it can be noticed that the deracemization rate per cycle decreases by increasing the amount of crystals employed. Thus, a $75 \mathrm{~m}$ long reactor (corresponding to 50 thermal cycles at $\tau_{\mathrm{c}}=60 \mathrm{~s}$ ) is adequate to reach $>96 \%$ purity of the target enantiomer when running at a feed suspension density of $45.4 \mathrm{~g} \mathrm{~L}_{\text {solvent }}{ }^{-1}$. However, by increasing the suspension density to 63.8 and $78.8 \mathrm{~g} \mathrm{~L}_{\text {solvent }}{ }^{-1}$, the same reactor delivers purity of only $83 \%$ and $85 \%$, respectively.

\section{Process productivity}

Table 1 presents an overview of the yield, productivity and enantiomeric purity attained for all continuous experiments calculated at the estimated number of cycles $(N)$ needed to

Table 1 Overview of yield $(Y)$, productivity $(P)$ and enantiomeric purity $\left(E_{f}\right)$ attained in the continuous deracemization experiments for various cycle residence times $\left(\tau_{\mathrm{c}}\right)$ and feed suspension densities $\left(\varphi_{\mathrm{s}, \mathrm{f}}\right)$ after $N$ cycles

\begin{tabular}{|c|c|c|c|c|c|}
\hline$\tau_{\mathrm{c}}^{a}(\mathrm{~s})$ & $\rho_{\mathrm{s}, \mathrm{f}}\left(\mathrm{g} \mathrm{L}_{\text {solvent }}{ }^{-1}\right)$ & $N(-)$ & $Y(\%)$ & $P\left(\mathrm{~g} \mathrm{~L}_{\text {solvent }}{ }^{-1} \mathrm{~h}^{-1}\right)$ & $E_{\mathrm{f}}(\%)$ \\
\hline 30 & 45.4 & 100 & 92.0 & 19.5 & 98.9 \\
\hline 60 & 63.8 & 100 & 98.2 & 14.3 & 98.0 \\
\hline 60 & 78.8 & 100 & 97.3 & 17.5 & 98.0 \\
\hline 120 & 45.4 & 50 & 93.6 & 9.2 & 96.0 \\
\hline 240 & 45.4 & 50 & 95.0 & 4.9 & 97.6 \\
\hline
\end{tabular}

${ }^{a} \tau_{\mathrm{c}}$ refers to the cycle residence time, where crystallization time is two times higher than dissolution time. ${ }^{b}$ Since shorter tube was impractical, $\tau_{\mathrm{c}}$ was decreased at $15 \mathrm{~s}$ by using the same tube as for $\tau_{\mathrm{c}}=30 \mathrm{~s}$ and running at double flow rate $\left(6 \mathrm{~mL} \mathrm{~min}^{-1}\right)$. In all other cases, flow rate was $3 \mathrm{~mL} \mathrm{~min}^{-1}$.

Table 2 Overview of productivities $(P)$ and enantiomeric purities $\left(E_{f}\right)$ attained in state-of-the-art batch deracemization experiments employing temperature cycles reported in the literature

\begin{tabular}{|c|c|c|c|}
\hline Study & Substance & $P^{a}\left(\mathrm{~g} \mathrm{~L}_{\text {solvent }}^{-1} \mathrm{~h}^{-1}\right)$ & $E_{\mathrm{f}}(\%)$ \\
\hline Suwannasang et al. ${ }^{3 b}$ & Precursor of paclobutrazol & 0.47 & $>99$ \\
\hline Li et $a l^{3 d}$ & Phenylalanine & 4.4 & 100 \\
\hline Oketani et al. ${ }^{3 e}$ & 2-Methoxy-naphtamide & 1.0 & 95 \\
\hline Breveglieri et $a .^{3 f}$ & $N$-(2-Methylbenzylidene)-phenylglycine amide & 1.8 & 100 \\
\hline Steendam et al. ${ }^{3 g}$ & Sodium bromate & 0.13 & $>99$ \\
\hline Cameli et $a l .{ }^{3 h}$ & 1 & 5.1 & 98.3 \\
\hline
\end{tabular}

${ }^{a}$ For cases where batch productivities were not reported, they were calculated by eqn (2) by replacing the term $N \cdot \tau_{\mathrm{c}}$ with the total batch time reported in each study. In cases where the yield, $Y$ was not reported, it was taken as 1 . Productivities correspond to the best case scenario reported in each study. 
achieve a steady-state of maximum enantiomeric purity $\left(E_{\mathrm{f}}>\right.$ $96 \%$ ) in the reactor outlet. An additional experiment is included in that table at an even shorter residence time of $\tau_{\mathrm{c}}$ $=15 \mathrm{~s}$ (not shown in Fig. 4) that was carried out in the same reactor as the one at $\tau_{\mathrm{c}}=30 \mathrm{~s}$ but using a double suspension flow rate $\left(6 \mathrm{~mL} \mathrm{~min}^{-1}\right)$. We note here in passing that changing the suspension flow rate at a constant residence time (by using different reactor lengths) did not affect the deracemization process $(\mathrm{ESI} \dagger)$. Therefore, in the range of parameters examined here, flow rate and reactor length can be viewed as two independent parameters that influence the deracemization process simply by their effect on $\tau_{\mathrm{c}}$. Nevertheless, a further increase in flow rate up to $12 \mathrm{~mL}$ $\min ^{-1}$ provoked clogging of the tubular reactor due to different relative velocities between solvent and crystals that caused particles to stick and form large aggregates. However, in all other conditions herein mentioned, no sign of clogging was observed, and the crystals appeared to be sufficiently suspended in the liquid. SEM images of the crystals before and after the runs in the flow reactor with different conditions of residence time, flow rate and suspension density are reported in ESI. $\dagger$

Table 1 shows that while an overall shorter residence time at a constant suspension density leads to a small negative impact on yield due to incomplete equilibration at the low temperature, substantially higher productivities at smaller reactor footprints are possible with shorter residence times. In fact, a total reactor length of just $75 \mathrm{~m}$ (100 cycles) is sufficient to produce up to $30.8 \mathrm{~g} \mathrm{~L}^{-1} \mathrm{~h}^{-1}$ of the preferred enantiomer at steady state, which is practically feasible. On the other hand, increasing the suspension density at a constant cycle residence time has a small negative impact on the productivity of the preferred enantiomer. While an increase in the feed suspension density should lead to higher productivity (eqn (3)), the effect is counterbalanced by the increased number of cycles needed to achieve enantiomeric purities $>96 \%$ due to the slower deracemization kinetics at higher suspension densities (Fig. 5).

As a comparison, Table 2 shows typical productivity and purity values obtained in state-of-the-art batch deracemization experiments employing temperature cycles reported in the literature. While a direct assessment is difficult due to the different kinetics in the various systems employed in the different studies, a comparison with Table 1 shows that productivity values of approximately an order of magnitude higher are obtained in the continuous deracemization process.

\section{Conclusions}

In summary, we have developed a continuous flow reactive crystallization process for accessing single enantiomer crystals of a conglomerate-forming pharmaceutical intermediate starting from nearly racemic suspensions. Within a tubular flow reactor, cycles of dissolution and crystallization of the suspension can be carried out by simply pumping the suspension through two thermal zones at high and low temperature. This configuration affords excellent heat transfer and allows to carry out thermal cycles in time periods as low as $15 \mathrm{~s}$, which are impossible to attain in batchwise operations. While in such short cycle times, suspension equilibration is not complete, the dissolution/ crystallization kinetics are greatly enhanced by operating most of the cycle at higher super(under)saturations. Using less than $100 \mathrm{~m}$ tubing, approximately $20 \mathrm{~g} \mathrm{~L}^{-1} \mathrm{~h}^{-1}$ of the preferred enantiomer at purities $>98 \%$ can be produced. Scale-up or scale-out of the method can be easily performed by increasing the tubing diameter or by adding parallel reactors and is foreseen to enable high throughput ondemand access of single enantiomers at industrial scale.

\section{Conflicts of interest}

There are no conflicts to declare.

\section{Acknowledgements}

This project has received funding from the European Union's Horizon 2020 research and innovation programme under the Marie Skłodowska-Curie grant agreement No 721290. This publication reflects only the author's view, exempting the Community from any liability. Project website: http://cosmicetn.eu/ Fabio Cameli thanks Prabhat Ranjan for providing the chiral crystals used in the experiments.

\section{References}

1 H. Lorenz and A. Seidel-Morgensern, Angew. Chem., Int. Ed., 2014, 53, 1218-1250.

2 (a) C. Viedma, Phys. Rev. Lett., 2005, 94, 065504; (b) W. L. Noorduin, W. J. P. Van Enckevort, H. Meekes, B. Kaptein, R. M. Kellogg, J. C. Tully, J. M. Mcbride and E. Vlieg, Angew. Chem., Int. Ed., 2010, 49, 8435-8438; (c) A. H. J. Engwerda, R. Maassen, P. Tinnemans, H. Meekes, F. P. J. T. Rutjes and E. Vlieg, Angew. Chem., Int. Ed., 2019, 58, 1670-1673; (d) C. Xiouras, A. Fytopoulos, J. H. Ter Horst, A. G. Boudouvis, T. Van Gerven and G. D. Stefanidis, Cryst. Growth Des., 2018, 18, 3051-3061; (e) C. Xiouras, A. Fytopoulos, J. Jordens, A. G. Boudouvis, T. Van Gerven and G. D. Stefanidis, Ultrason. Sonochem., 2018, 43, 184-192.

3 (a) C. Viedma and P. Cintas, Chem. Commun., 2011, 47, 12786; (b) K. Suwannasang, A. E. Flood, C. Rougeot and G. Coquerel, Cryst. Growth Des., 2013, 13, 3498-3504; (c) F. Cameli, C. Xiouras and G. D. Stefanidis, CrystEngComm, 2018, 20, 2897; (d) W. W. Li, L. Spix, S. C. A. De Reus, H. Meekes, H. J. M. Kramer, E. Vlieg and J. H. Ter Horst, Cryst. Growth Des., 2016, 16, 5563-5570; (e) R. Oketani, M. Hoquante, P. Cardinael and G. Coquerel, Cryst. Growth Des., 2018, 18, 6417-6420; $(f)$ F. Breveglieri, G. M. Maggioni and M. Mazzotti, Cryst. Growth Des., 2018, 18, 1873-1881; $(g)$ R. R. E. Steendam and J. H. ter Horst, Cryst. Growth Des., 2018, 18, 3008-3015; (h) F. Cameli, J. H. ter Horst, R. R. E. Steendam, C. Xiouras and G. D. Stefanidis, Chem. - Eur. J., 2020, 26, 1344-1354. 
4 (a) K. Suwannasang, G. Coquerel, C. Rougeot and A. E. Flood, Chem. Eng. Technol., 2014, 37, 1329-1339; (b) H. Katsuno and M. Uwaha, Phys. Rev. E, 2016, 93, 1-10; (c) B. Bodák, G. M. Maggioni and M. Mazzotti, Cryst. Growth Des., 2018, 18, 7122-7131.

5 (a) B. Gutmann, D. Cantillo and C. O. Kappe, Angew. Chem., Int. Ed., 2015, 54, 6688-6728; (b) A. R. Bogdan, S. L. Poe, D. C. Kubis, S. J. Broadwater and D. T. McQuade, Angew. Chem., Int. Ed., 2009, 48, 8547-8550; (c) S. D. Schaber, D. I. Gerogiorgis, R. Ramachandran, J. M. B. Evans, P. I. Barton and B. L. Trout, Ind. Eng. Chem. Res., 2011, 50, 10083-10092; (d) S. L. Lee, T. F. O'Connor, X. Yang, C. N. Cruz, S. Chatterjee, R. D. Madurawe, C. M. V. Moore, L. X. Yu and J. Woodcock, J. Pharm. Innov., 2015, 10, 191-199; (e) R. L. Hartman, J. P. McMullen and K. F. Jensen, Angew. Chem., Int. Ed., 2011, 50, 7502-7519.

6 S. A. Raza, U. Schacht, V. Svoboda, D. P. Edwards, A. J. Florence, C. R. Pulham, J. Sefcik and I. D. H. Oswald, Cryst. Growth Des., 2018, 18, 210-218.
7 T. McGlone, N. E. B. Briggs, C. A. Clark, C. J. Brown, J. Sefcik and A. J. Florence, Org. Process Res. Dev., 2015, 19, 1186-1202.

8 A. Adamo, R. L. Beingessner, M. Behnam, T. F. Jamison, K. F. Jensen, J.-C. M. Monbaliu, A. S. Myerson, E. M. Revalor, D. R. Snead, T. Stelzer, N. Weeranoppanant, S. Y. Wong and P. Zhang, Science, 2016, 352, 61-67.

9 (a) T. Köllges and T. Vetter, Cryst. Growth Des., 2017, 17, 233-247; (b) A. Majumder, Processes, 2018, 6, 247; (c) A. Majumder and Z. Nagy, Pharmaceutics, 2017, 9, 55.

10 (a) D. L. Comins, S. Schilling and Y. Zhang, Org. Lett., 2005, 7, 95-98; (b) V. Agouridas, F. Capet, A. Couture, E. Deniau and P. Grandclaudon, Tetrahedron: Asymmetry, 2011, 22, 1441-1447.

11 (a) F. Yagishita, H. Ishikawa, T. Onuki, S. Hachiya, T. Mino and M. Sakamoto, Angew. Chem., Int. Ed., 2012, 51, 13023-13025; (b) R. R. E. Steendam, M. C. T. Brouwer, E. M. E. Huijs, M. W. Kulka, H. Meekes, W. J. P. Van Enckevort, J. Raap, F. P. J. T. Rutjes and E. Vlieg, Chem. Eur. J., 2014, 20, 13527-13530. 